\title{
Using vulnerability indicators to develop resilience networks: a similarity approach
}

\author{
Stephanie E. Chang ${ }^{1}$ Jackie Z. K. Yip ${ }^{2}$ • \\ Shona L. van Zijll de Jong ${ }^{3} \cdot$ Rebecca Chaster $^{3}$ • \\ Ashley Lowcock ${ }^{3}$
}

Received: 12 September 2014/ Accepted: 9 May 2015/Published online: 20 May 2015

(C) The Author(s) 2015. This article is published with open access at Springerlink.com

\begin{abstract}
This paper proposes a new approach to developing and utilizing vulnerability indicators, which is based on the concept of similarity. Methods for assessing the disaster vulnerability of communities through quantitative indices are established in research and practice. They are typically used to identify which cities or other spatial units are most susceptible to losses from storms, floods, and other hazards; however, their utility for taking action to reduce vulnerability has been found to be limited. In contrast, the method developed here quantifies vulnerability profiles for purposes of identifying places that are similarly vulnerable. Such an approach can facilitate sharing of knowledge, resources, and successful practices that are relevant to a particular community's circumstances. The approach is demonstrated in a preliminary application to coastal communities in British Columbia, Canada.
\end{abstract}

Keywords Hazards · Disasters · Vulnerability · Resilience - Quantitative methods · Indicators

\section{Introduction}

The concept of differential vulnerability to natural hazards - that groups within society are not equally at risk from the adverse effects of hazard events but are, rather, differently predisposed to harm-is well established in both research and practice. Predisaster

Stephanie E. Chang

stephanie.chang@ubc.ca

1 Institute for Resources, Environment, and Sustainability (IRES), School of Community and Regional Planning (SCARP), University of British Columbia, 433-6333 Memorial Rd., Vancouver, BC V6T 1Z2, Canada

2 IRES, University of British Columbia, 429-2202 Main Mall, Vancouver, BC V6T 1Z4, Canada

3 SCARP, University of British Columbia, 433-6333 Memorial Rd., Vancouver, BC V6T 1Z2, Canada 
conditions such as poverty, chronic illness, and poor quality housing are known to make some social groups more likely to suffer losses when disasters strike and to have more difficulty in recovering. The concept of vulnerability can also be extended to places. In addition to social, demographic, and economic aspects, some communities face high natural hazard risk due to their location, for example, in seismic zones or floodplains. Coastal cities are especially vulnerable to storm surge and flooding, and these hazards are expected to be exacerbated by subsidence and sea-level rise.

While case studies are essential for providing insights into the causes, processes, and contexts of vulnerability, comparative studies are needed to identify patterns and support prioritization (National Research Council 2006). For example, an assessment of 136 coastal cities around the world conducted by Hallegatte et al. (2013) has found that not only are total potential flood losses increasing rapidly, but expected economic losses are concentrated in only a few, particularly vulnerable cities. Many other studies, as reviewed below, have utilized indicator-based approaches to identify "hotspots" of vulnerability. Efforts are also emerging to quantify the related concept of disaster resilience (e.g., Bruneau et al. 2003; Cutter et al. 2008), which has been defined as "the ability to prepare and plan for, absorb, recover from, and more successfully adapt to adverse events" (National Research Council 2012, p. 1). Such systematic assessments are needed to inform public policy (e.g., Mustafa et al. 2011; National Research Council 2012).

This paper proposes a new approach to using vulnerability indicators to bridge knowledge and practice in reducing disaster risk and fostering disaster resilience. Rather than identifying places that may be most vulnerable, the approach is intended to identify places that are similarly vulnerable, in order to facilitate building networks for disaster resilience. This objective is motivated by the recognition that learning is important for resilience, for example, learning lessons from other communities' experiences of disasters and their actions to reduce disaster vulnerability. Finding cases and lessons that are the most relevant, however, is difficult. The approach proposed here can provide systematic guidance to help communities learn from places that face similar challenges, rather than simply drawing on sources that are most recent, familiar, or available.

The paper is organized as follows. In Sect. 2, the literature on quantitative indicators of disaster vulnerability of communities is first reviewed, focusing on methodological approaches, applications, and critiques. Emphasis is placed on vulnerability of coastal communities. A similarity-based approach is then proposed in Sect. 3, which is adapted from well-established methods in other fields of application. Section 4 demonstrates the concept in a prototype application to coastal communities in British Columbia, Canada. Section 5 elaborates on the idea of implementing vulnerability indicators to develop resilience networks and concludes with a discussion of opportunities, limitations, and future research needs.

\section{Vulnerability and risk indicators}

Numerous approaches have been developed for quantifying indicators of vulnerability to environmental change, and vulnerability indicators have been applied around the world. More recently, as discussed below, indicator approaches have extended beyond vulnerability to the concept of resilience. Of particular relevance here are those that focus on the community scale (e.g., cities rather than households or nations), on vulnerability to natural hazards (e.g., storms rather than climate change generally), and on socioeconomic 
vulnerability and its intersection with biophysical dimensions (e.g., human communities rather than ecosystems). The following review emphasizes indicator approaches that have been developed for coastal communities and coastal hazards, based on the premise that some key aspects of vulnerability are specific to coastal conditions and should be explicitly acknowledged. It further emphasizes recent developments, including emerging critiques and gaps, and pays particular attention to the potential uses of vulnerability indicators.

The Social Vulnerability Index (SoVI) developed by Cutter et al. (2003) represents one of the major approaches for quantifying community vulnerability to hazards. Based on a hazards-of-place model, it conceptualizes overall vulnerability as deriving from the interaction between biophysical and social vulnerabilities. Focusing on the latter, the SoVI framework provides an approach for quantitatively comparing the relative social vulnerability of places. The original SoVI framework was applied to all counties comprising the USA and included 42 variables that characterized social, demographic, economic, and built environment attributes of communities. Importantly, variable selection was informed by an extensive theoretical and empirical literature on hazards and disaster vulnerability. The 42 variables, which were implemented largely with census data, were reduced to 11 factors by using a statistical approach that accounts for correlation between variables. These factors were then combined in an unweighted index that quantified the relative degree of social vulnerability for each county. Results identify the most vulnerable communities in the USA.

Indicator-type approaches have more recently been developed and applied around the world, including several that specifically address the vulnerability of coastal communities. A number of vulnerability indices integrate elements of social vulnerability with physical vulnerability in the context of specific coastal hazards, for example, hurricanes and storm surge (Rygel et al. 2006; Bjarnadottir et al. 2011), tsunamis (Wood et al. 2010), marine oil spills (Santos et al. 2013), coastal erosion (McLaughlin and Cooper 2010), loss of coastal wetlands due to urbanization (Huang et al. 2012), and coastal flooding and sea-level rise (Wu et al. 2002; Balica et al. 2012; Felsenstein and Lichter 2014).

Methodologically, vulnerability indicators have been refined through greater attention to issues of spatial scale, with limited attention to multi-scalar interactions. Some studies have developed vulnerability indicators at neighborhood or smaller spatial scales, such as census blocks (e.g., Wood et al. 2010; Oulahen et al. 2015). Felsenstein and Lichter (2014) aggregated household-level data to the community level, which enabled an analysis of intracommunity differentials across subpopulations in the hazard zones. McLaughlin and Cooper (2010) explored coastal vulnerability indices at national, local, and site levels; they noted that index development should consider spatial scales appropriate to the hazard, to data availability, and to management decisions.

Innovations have also been made in considering dynamics, or changes over time, in vulnerability indicator analysis. Using SoVI, Cutter and Finch (2008) provided a retrospective assessment of how social vulnerability patterns across the USA have changed between 1960 and 2000. Other coastal vulnerability studies have prospectively analyzed how vulnerability patterns may change in future, particularly in the context of hazard shifts related to climate change (Bjarnadottir et al. 2011; Balica et al. 2012).

An important advance has been the incorporation of variables that describe institutional dimensions of places that relate, for example, to governance arrangements and risk management. The attention to institutional dimensions reflects growing attention to indicators of resilience (for a recent review, see National Research Council 2012). (As noted in Sect. 1 above, resilience overlaps conceptually with but is not the same as vulnerability.) Cutter et al. (2008) propose a disaster resilience of place (DROP) model that would include 
ecological, social, economic, institutional, infrastructure, and community competence indicators. Institutional variables could include availability of hazard mitigation plans, emergency services, and zoning and building standards that reduce risk. Peacock (2010) developed a Community Disaster Resilience Index that is similarly framed around five forms of capital (natural, physical, human, social, and financial) but explicitly referenced to the phases of the disaster cycle (mitigation, preparedness, response, recovery). This framework allows capturing of institutional variables such as building inspectors or percent of population covered by zoning regulations. Although applied to US Gulf Coast counties, it is not specific to coastal hazards. Among coastal vulnerability or resilience indicator studies, Balica et al. (2012) considered flood hazard maps, flood protection, and uncontrolled planning zones.

In adapting vulnerability indicator approaches to different contexts, different types of data sources have been explored. Holand and Lujala (2013) discuss conceptual applicability, data availability, and data appropriateness in the process of adapting SoVI to other countries and contexts. In many cases, particularly where statistical data are unavailable, unreliable, or incomplete, processes of data collection have been more participatory. Experts and local stakeholders have been engaged to identify indicators, to design indices, to incorporate local knowledge of hazard and vulnerability conditions, to provide weights for indicators, and to ensure appropriateness to local contexts (e.g., Huang et al. 2012; Kienberger 2012; Orencio and Fujii 2012; Torresan et al. 2012). After developing a SoVItype index using statistical data, Oulahen et al. (2015) engaged municipal government staff in several Canadian municipalities to validate, weight, and revise it.

Despite the numerous applications and methodological innovations, however, the basic motivation for developing vulnerability indicators has remained remarkably consistent. Whether explicitly or implicitly, nearly all such studies have sought to assess the relative vulnerability of places (an exception is Burton (2010), which sought to improve hurricane loss models). Places might be mapped according to a vulnerability score or ranked. A common objective is to identify areas of especially high vulnerability in order to support allocating resources and making decisions, plans, and policies to reduce this vulnerability. For example, Wood et al. (2010) sought to identify hotspots of social vulnerability to help emergency managers in disaster risk reduction planning. Chakraborty et al. (2005) identified patterns of social vulnerability to indicate where special assistance would be needed in evacuation. Balica et al. (2012) suggest that indicators can be used to help explore changing vulnerability and adaptation options for climate change. Vulnerability indicators, if appropriately formulated and tracked over time, can in principle be used to monitor progress toward risk reduction and resilience goals (National Research Council 2012).

While vulnerability indicators have been widely applied, the limitations of the approach have also been recognized (e.g., Fekete 2012). Conceptually, vulnerability is a complex phenomenon involving numerous factors, many of which can only be imperfectly suggested by quantifiable variables. Moreover, vulnerability arises from the interaction of factors, and the interaction occurs in a particular context. No single composite index can be expected to capture such complexity thoroughly, and some analysts have argued for the use of disaggregated indicators rather than composite indices (e.g., Adger et al. 2004). Data issues are numerous, as alluded to above. Methodological issues include how to select and weight indicators (e.g., Jones and Andrey 2007, Tate 2012). Furthermore, vulnerability indicators are very difficult to validate (Cutter and Finch 2008).

Other critiques pertain to the usability of vulnerability indicators. Some analysts suggest that despite their intent, vulnerability analysis has made few tangible contributions to public policy (Mustafa et al. 2011). Communicating large quantities of data to stakeholders 
is challenging, and potential users may not readily accept indices that do not correspond to their local knowledge; further, they may prefer to develop combinations of individual indicators that are more locally pertinent than a composite index (Oulahen et al. 2015). Involving potential users can be important for increasing the likelihood that vulnerability indicators will be used in practice. Indeed, the design of vulnerability indicators should be driven by their intended use, thus implying the need for a multiplicity of approaches (Birkmann et al. 2013).

Here, we propose that vulnerability indicators can be valuable for a new purpose: Rather than identifying the most vulnerable places, they can be used to match places that are similarly vulnerable. We argue that if applied for this purpose, vulnerability indicators can be effective in facilitating knowledge transfer, learning, and resource sharing for reducing vulnerability and risk. Such an approach should enable comparison of communities in terms of different dimensions of vulnerability; hence, disaggregated similarity indicators are needed, along with overall (composite) measures. While not necessarily requiring new conceptual frameworks, this utilization demands a different methodological approach, as described and demonstrated below.

\section{A similarity-based approach}

\subsection{Similarity index methods}

Methods for quantifying similarity, such as the Jaccard index or the Pearson correlation coefficient, are well established in many fields. Similarity indices are applied in ecology, for example, to assess similarity between ecological communities in terms of their species composition (e.g., Hastings et al. 2012), in genetics to characterize similarity between gene profiles (e.g., Deshpande et al. 2013), and in psychology to measure similarity between personality profiles (e.g., Furr and Wood 2013). In some cases, the presence or absence of common features is of interest, while in others, the degree of commonality is important and can be assessed by various measures of distance.

In adapting such measures for purposes of comparing communities' vulnerability profiles, it is important to consider several practical requirements. The similarity measure should be able to handle different types of data. Some types of indicators may be binary, such as whether or not a community has adopted a bylaw that regulates development on floodplains. Other indicators could be nominal or ordinal categorical variables (e.g., measured as high/medium/low), or continuous (e.g., measured as percent of population). It is also important for the similarity measure to be able to handle different amounts and types of data that might be available for different communities. It should be possible to implement the similarity measure even in cases where some data are missing. Furthermore, the measure should allow for comparisons along individual or subgroups of vulnerability indicators, such as size of built environment or social vulnerability, in addition to overall vulnerability profile.

\subsection{Hazard Vulnerability Similarity Index}

Based on these considerations, we propose a similarity measure that is adapted from Gower's general similarity coefficient $S_{\text {Gower }}$, which was originally proposed by Gower 
(1971) and is widely used for mixed data types (Gan et al. 2007). Here, the Hazard Vulnerability Similarity Index (HVSI) is defined as:

$$
\operatorname{HVSI}(\boldsymbol{x}, \boldsymbol{y})=\sum_{k=1}^{n} w\left(x_{k}, y_{k}\right) s\left(x_{k}, y_{k}\right) / \sum_{k=1}^{n} w\left(x_{k}, y_{k}\right)
$$

where $\boldsymbol{x}$ and $\boldsymbol{y}$ describe two communities, respectively, and are comprised of $n$ vulnerability indicators. The quantity $s\left(x_{k}, y_{k}\right)$ measures the similarity between the $k$ th indicator of $\boldsymbol{x}$ and $\boldsymbol{y}$, and $w\left(x_{k}, y_{k}\right)$ is the weighting of the $k$ th attribute. Weights $w$ are equal to 1 when the comparison is valid and 0 when it is invalid. Both $s\left(x_{k}, y_{k}\right)$ and $w\left(x_{k}, y_{k}\right)$ are defined for different types of data, as shown in Table 1 .

The range $R_{k}$ for the $k$ th attribute is defined as the difference between the maximum and minimum values over all communities being analyzed.

HVSI can range from 0 , indicating complete dissimilarity, to 1 , indicating the two communities are identical in the profiles of their vulnerability indicators. The coefficient would be undefined when there is no valid comparison in any of the attributes (i.e., when $w_{1}=w_{2}=\cdots=w_{n}=0$ ). A strength of this formulation is that HVSI, like $S_{\text {Gower }}$, can handle the challenge of fragmented data availability, since it only includes attributes that have data available for the comparison.

HVSI differs from the original $S_{\text {Gower }}$ formulation in its treatment of binary data types: When $x_{k}=y_{k}=0, s\left(x_{k}, y_{k}\right)=1$ (rather than 0 , as in $S_{\text {Gower }}$ ). In the current application, the absence of an attribute (e.g., the absence of a floodplain bylaw) is relevant for determining the similarity of communities. The absence of information about whether or not an attribute is present, in contrast, would be treated as missing data, so that $w\left(x_{k}, y_{k}\right)=0$.

Since it is possible for two communities to have an HVSI of 1 even if the comparison were made on the basis of only 1 out of $n$ indicators (the remaining $n-1$ being invalid comparisons with missing data), it is useful to have information on the completeness of data on which the comparison is made. In addition to the Gower-type similarity coefficient defined in Eq. 1 and Table 1, the HVSI is further specified with a completeness index $G(\boldsymbol{x}$, $y$ ) that gives the user an indication of the similarity score's quality:

$$
G(\boldsymbol{x}, \boldsymbol{y})=\frac{\sum_{k=1}^{n} w\left(x_{k}, y_{k}\right)}{n}
$$

The completeness index ranges from 0 to 1 , where 0 indicates a situation in which the two communities could not be compared on any of the $n$ indicators, and 1 indicates that all $n$ indicators were used in the comparison. When assessing the similarity of places, it is useful to consider both HVSI and the corresponding value of $G$.

Note that both the similarity index HVSI and the completeness index $G$ can be evaluated for the entire set of indicators or for any subgroup of them. For example, an

Table 1 Implementation of different types of data in HVSI

\begin{tabular}{lll}
\hline Type of data $\mathrm{x}_{k}, y_{\mathrm{k}}$ & $s\left(x_{k}, y_{k}\right)$ & $w\left(x_{k}, y_{k}\right)$ \\
\hline Continuous or ordinal & $\begin{array}{r}s\left(x_{k}, y_{k}\right)=1-\frac{\left|x_{k}-y_{k}\right|}{R_{k}} ; \text { where } R_{k} \\
\text { is the range of the } k \text { th indicator }\end{array}$ & $\begin{aligned} w\left(x_{k}, y_{k}\right)=0 \\
w\left(x_{k}, y_{k}\right)=1 \quad \text { if } x_{k} \text { or } y_{k} \text { is missing; } \\
\text { otherwise }\end{aligned}$ \\
$\begin{aligned} s\left(x_{k}, y_{k}\right)=1 \quad \text { if } x_{k}=y_{k} ; \\
s\left(x_{k}, y_{k}\right)=0\end{aligned}$ & otherwise \\
\hline
\end{tabular}


economic subgroup might be defined that includes several economic vulnerability indicators. Two communities could then be compared for their overall similarity in vulnerability profile, as well their similarity in economic vulnerability only.

In the HVSI framework, a distinction is made between indicators and variables. HVSI is specified in terms of a finite number of indicators, each of which corresponds conceptually to a dimension of hazard vulnerability and each of which could be measured by different variables. For example, the concept of economic size is important to vulnerability, as it reflects financial resources available to a community. In the HVSI framework, economic size is treated as an indicator that could be measured by different variables such as number of full-time jobs, number of full-time plus part-time jobs, number of businesses, total income, and gross regional product. Not all communities would have data on all of these variables, but most communities should have at least one. In comparing two communities, any of these variables could be used to measure economic size, provided that data are available for both communities, in other words, provided that a valid comparison is possible. In practice, when an indicator can be measured by more than one variable, it would be measured in the HVSI framework by the first variable in an ordered list for which a valid comparison can be obtained.

Note that because the HVSI measures similarity in vulnerability profile, rather than relative degree of vulnerability, it is not necessary for all of the constituent indicators to be specified in ways that imply greater or lesser vulnerability. Nominal variables are permitted that do not have any assumed ordering of hazard vulnerability. For example, an indicator $k$ that represents coastal landform can be specified, where $k=1$ might indicate sandy beaches, $k=2$ rocky cliffs, etc. Rather than being associated with greater or lesser vulnerability, such an indicator would be useful for indicating different types of vulnerability.

\section{Strait of Georgia application}

Implementation of the HVSI approach is demonstrated here through a limited application to the Strait of Georgia in southern British Columbia, Canada. The study area is very diverse: Communities range from highly urbanized municipalities in the Metro Vancouver region (on the mainland) to cities on Vancouver Island and small, remote towns and villages isolated by water and/or mountains. This demonstration focuses on the 50 largest communities in the region, whose populations range from 4,400 to 603,500 . The region faces a number of coastal hazards, including winter storms and storm surge, earthquake, tsunami, and longer-term hazards associated with sea-level rise. Many communities in the region are reliant on ferries for transport of goods and people.

The HVSI concept is demonstrated with the indicator framework specified in Table 2. In the interest of providing a simplified demonstration, this example has fewer indicators and variables than would be used in a full application. For example, no attempt is made here to represent all the social vulnerability indicators that are well-established in the literature, much less the entire range of indicators that have been proposed in other studies. Only one variable is selected per indicator, based largely on data availability in the study area. While many variables in this example are continuous (e.g., percentages and dollars), some are categorical. In this demonstration, data for all variables were available for all communities; thus, the index $G$ is 1.0 in all cases, indicating a complete dataset. 
Table 2 HVSI Demonstration Framework

\begin{tabular}{|c|c|c|c|}
\hline Capital & Indicator & Variable & Variable type \\
\hline \multirow[t]{5}{*}{ Economic } & Size & No. businesses & Continuous \\
\hline & Spatial structure & $\%$ Commuting outside community & Continuous $(\%)$ \\
\hline & Composition & $\%$ Employed in primary sector & Continuous $(\%)$ \\
\hline & Participation & $\%$ Unemployed & Continuous $(\%)$ \\
\hline & Change & $\%$ Change in no. businesses, last 5 years & Continuous $(\%)$ \\
\hline \multirow[t]{5}{*}{ Social } & Size & Population & Continuous \\
\hline & Spatial structure & $\%$ Population living on coast & Continuous $(\%)$ \\
\hline & Composition & $\%$ Population over 65 years old living alone & Continuous $(\%)$ \\
\hline & Participation & $\begin{array}{l}\text { \% Population cannot speak English or French } \\
\text { (i.e., official languages) }\end{array}$ & Continuous $(\%)$ \\
\hline & Change & $\%$ Population moved in within last 5 years & Continuous $(\%)$ \\
\hline \multirow[t]{5}{*}{ Built } & Size & $\$$ Value of built environment & Continuous \\
\hline & Spatial structure & Commercial center on coast (yes/no) & Binary \\
\hline & Composition & Structural flood protection (yes/no) & Binary \\
\hline & Participation & No. transport connections & Continuous \\
\hline & Change & $\%$ Residences built before 1960 & Continuous $(\%)$ \\
\hline \multirow[t]{5}{*}{ Natural } & Size & Coastline length & Continuous \\
\hline & Spatial structure & Type of flood hazard & Nominal \\
\hline & Composition & Landform & Nominal \\
\hline & Participation & Protected areas (yes/no) & Binary \\
\hline & Change & Projected sea-level change, 100 years (ranges) & Ordinal \\
\hline
\end{tabular}

In a similar manner to the literature reviewed above (e.g., Cutter et al. 2008; Peacock 2010; Birkmann et al. 2013), the framework is structured around major types of capital: economic, social, built environment, and natural environment. It is further structured around key dimensions of community capitals, specified here as: size, spatial structure, composition, participation, and change. These dimensions provide one way of synthesizing concepts reflected in the broad range of indicators in the disaster vulnerability literature. The "size" dimension captures such concepts as resources available, as well as overall exposure to hazard risk. "Spatial structure" relates more specifically to geospatial aspects of the community that affect risk, while "composition" refers to important nonspatial aspects of community structure and type (e.g., sectoral structure of the economy, diversity, differential vulnerability of population subgroups). "Participation" relates to concepts of networks, access, and integration (or, conversely, isolation). "Change" incorporates aspects of temporal dynamics, in terms of hazard and/or exposure, vulnerability, and community capacity. Such a framework is advantageous in ensuring some consistency across capitals so that results are not skewed toward those aspects for which data are plentiful and many indicators could readily be created. Similarly, it encourages attention to be paid to aspects of vulnerability that are important but may not be immediately apparent (e.g., temporal change). With four types of capital and five key dimensions, 20 indicators in total are used in this demonstration.

Data were obtained primarily from the 2011 Census of Canada and the 2011 National Household Survey. Supplementary sources included the 2006 Census, a business database from BC Stats (the provincial statistical agency), DataBC (a provincial spatial database), 
and CanCoast (a database developed by Natural Resources Canada, a federal government science entity). Visual inspection of map data was used to develop a few of the variables (i.e., "commercial center on coast," "type of flood hazard" and "protected areas Y/N"). GIS analysis was used to develop one variable ("number of transport connections").

To demonstrate the approach, one community, the district of Squamish, was selected as the focus community. The HVSI was computed for each of the other 49 communities with reference to Squamish, that is, to quantify their similarity levels to Squamish in terms of vulnerability profile. Such an analysis could support decision-makers and planners in Squamish in identifying other communities in the region who share the district's vulnerability attributes. Results are shown in the sequence of maps in Figs. 1, 2 and the histogram in Fig. 3.

Figure 1 shows how similar the other 49 communities are to Squamish in terms of overall vulnerability profile, considering the 20 indicators listed in Table 2 above. The numerical HVSI results indicate that the greatest similarity is with the City of Nanaimo on Vancouver Island. This similarity is moderately high $(\mathrm{HVSI}=0.85)$ and, as shown in Fig. 3, comparable to the HVSI with a few other communities in the region; there are no communities to which Squamish is highly similar (HVSI >0.9). These results are consistent with the observation that Squamish is a somewhat unusual community in the region, being a rapidly growing small town situated at the head of Howe Sound.

Figure 2 provides further insight by identifying HVSI patterns in terms of the constituent capitals. In terms of economic vulnerability profile (Fig. 2a), Squamish is quite similar to many of the more urbanized communities in the Metro Vancouver region. Its social vulnerability profile (Fig. 2b), by contrast, is much more similar to small towns along the coast of Vancouver Island than that to the Metro Vancouver municipalities. In

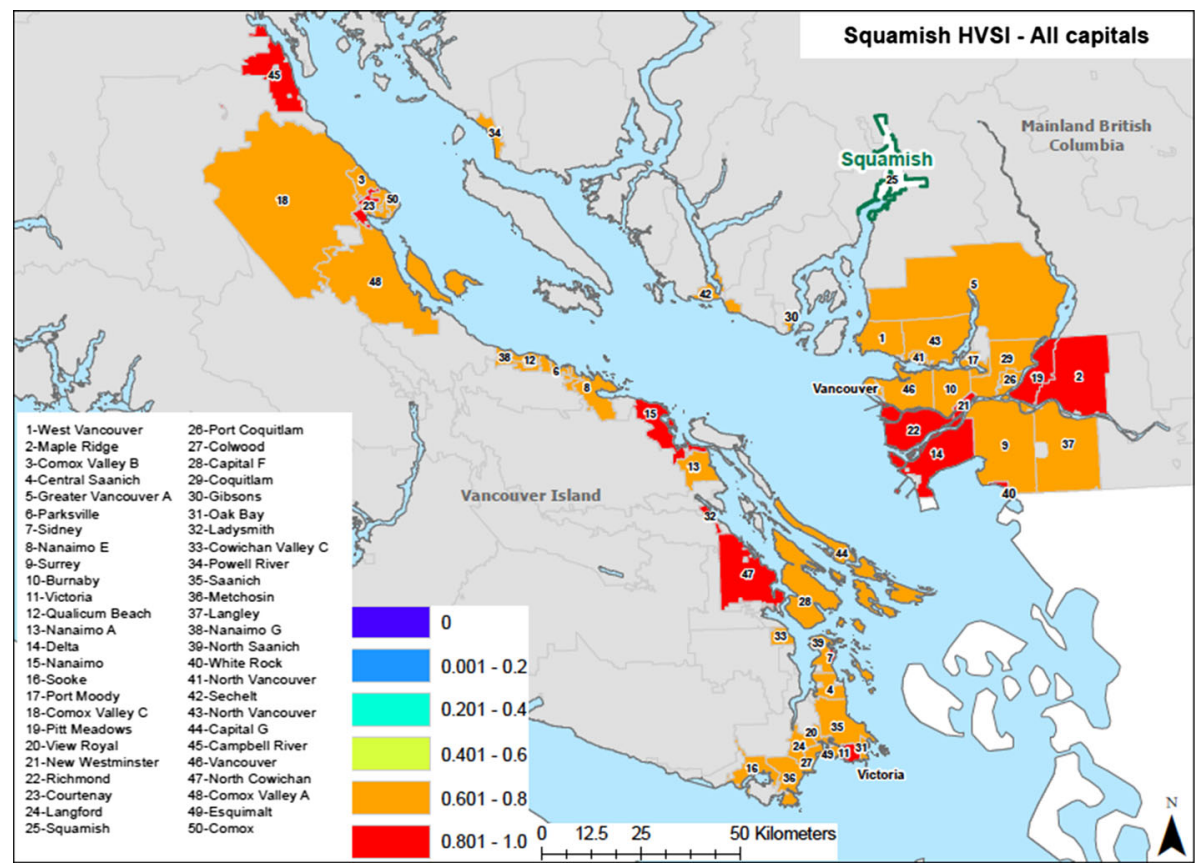

Fig. 1 Overall similarity of Strait of Georgia communities to Squamish 

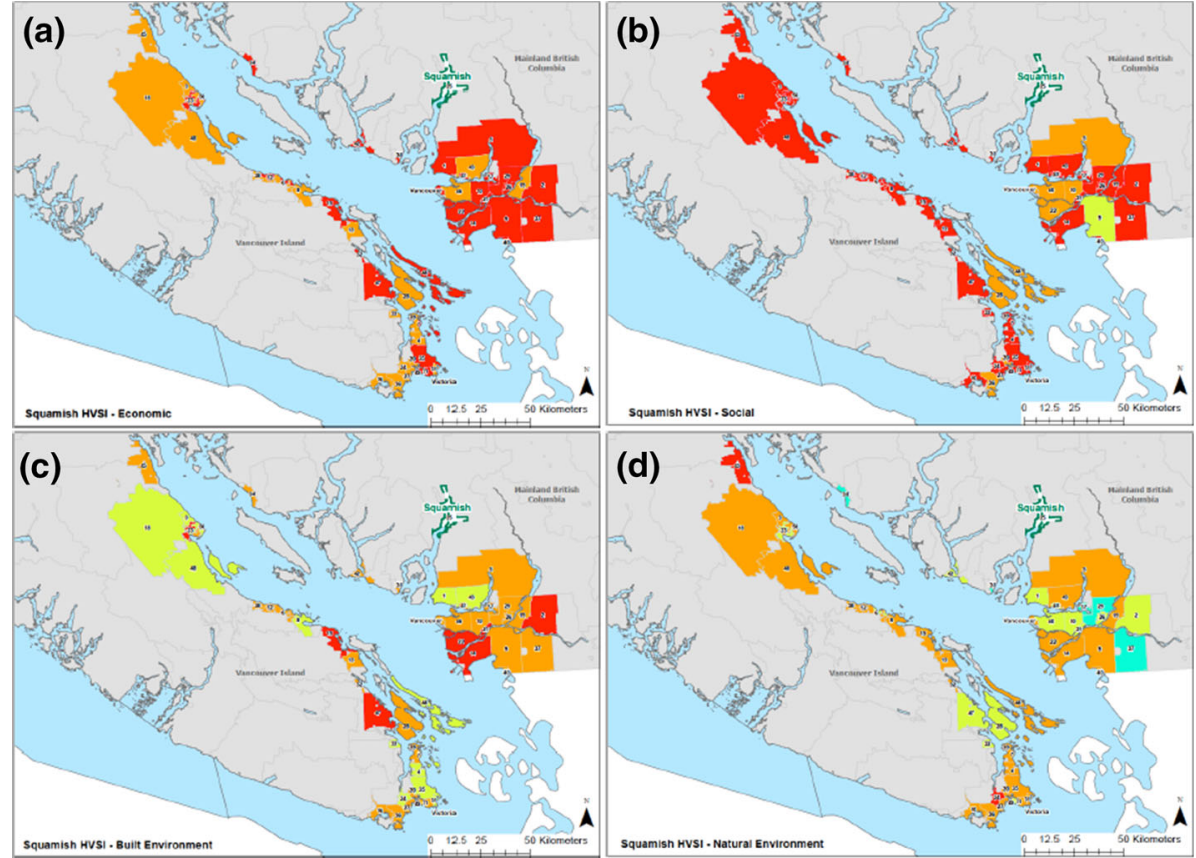

Fig. 2 Similarity of Strait of Georgia communities to Squamish, by type of capital: a economic, b social, c built, d natural

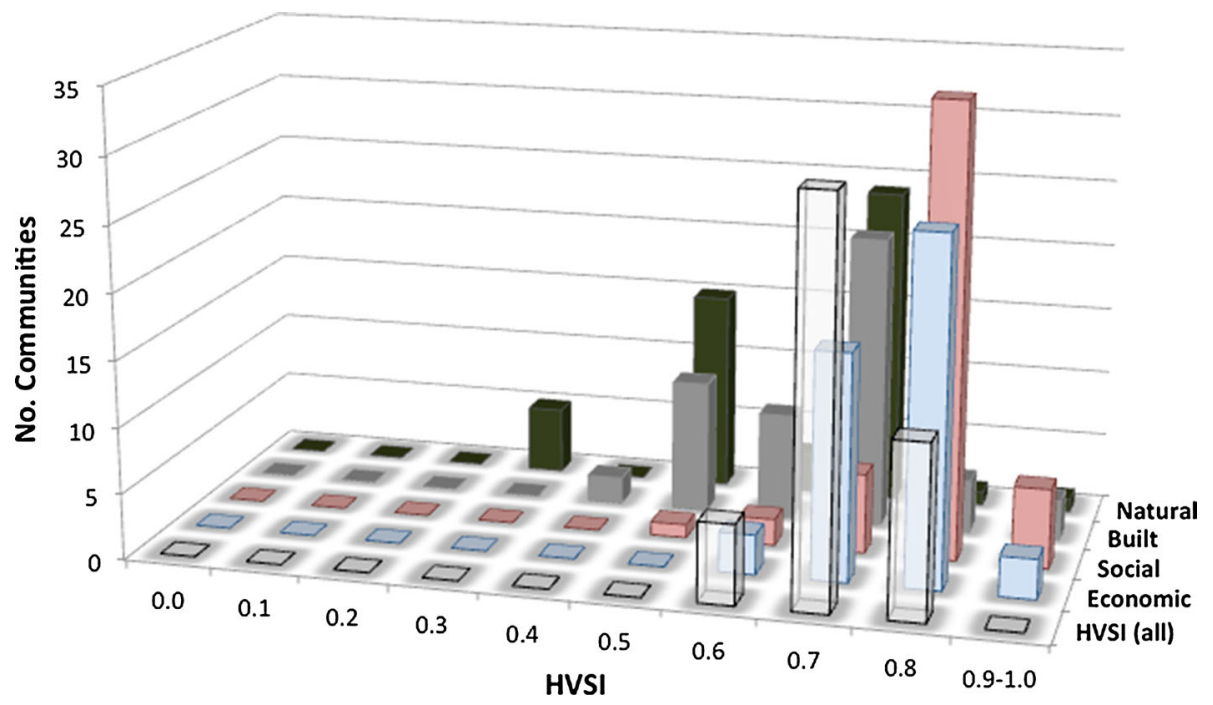

Fig. 3 Distribution of HVSI values for similarity to Squamish, overall and by type of capital

terms of built environment characteristics (Fig. 2c), Squamish is quite dissimilar to most places in the region, but very similar to a few. Its natural environment characteristics (Fig. 2d) are highly similar to Campbell River $\left(\mathrm{HVSI}_{N}=0.99\right)$ on the northernmost 
reaches of the study area and very dissimilar to many of the Metro Vancouver municipalities located on the Fraser River delta. Nanaimo is moderately similar to Squamish along all of these dimensions. Such findings can help identify communities that have vulnerability attributes in common and that could share information on appropriate risk reduction approaches. For example, if Squamish planners are interested in developing green infrastructure approaches for reducing future flood risks, they could investigate how and if Campbell River (highly similar to Squamish in terms of natural environment) has used green infrastructure.

Refinement of the indicator set remains an important area for further research. One key research need is the incorporation of institutional capital and associated indicators, including aspects of governance, planning, and local capacity (e.g., for emergency response and climate change adaptation). For example, a key variable would be whether or not a community has bylaws or other land-use plans for restricting coastal development in hazard-prone areas. The HVSI approach could then be used to identify not just instances of similarity, but also of difference. Planners in a community without such land-use controls could use the HVSI approach to identify other communities that are different in that they already have land-use control but yet similar in terms of other vulnerability attributes (e.g., subject to both coastal and riverine flooding, with existing coastal defenses such as dikes). Information could then be shared regarding land-use planning that is relevant to the particular economic, social, built, and natural environmental context.

As discussed in Sect. 2 above, the ability to customize combinations of indicators is important for users to query vulnerability indicator data in ways that would be most informative for local concerns. For example, an economic stakeholder (e.g., Chamber of Commerce) may be most interested in economic indicators, while emergency managers and mitigation planners may focus on hazard exposure variables for coastal flooding (e.g., commercial center on coast, type of flood hazard, landform, structural flood protection) to identify other similar communities. Such transparency may also be helpful in prioritizing data collection and identifying foci for more detailed vulnerability assessments. Further research is needed to identify specific variables that may be most informative for purposes of sharing information on planning for coastal risk reduction.

Other future refinements of the methodology are warranted. The implications of indicator specification should be explored; for example, the population size indicator could be specified as either a categorical or a continuous variable. The former is advantageous in having a clearly defined range and facilitating the categorization of places; on the other hand, a disadvantage is that it introduces discontinuities between size categories. Future research should calibrate HVSI and provide guidelines for its interpretation; this will require expanding the dataset of communities and variables. In addition, the HVSI method was designed to be able to handle missing data, and this aspect should be empirically explored. This would also allow development of guidelines for interpreting and visualizing the completeness index $(G)$ so as to help the user interpret the results.

The approach can also be extended in a number of ways for risk reduction. The database and analytical results could be integrated with other spatial information systems such as flood forecasting and warning systems. An intriguing area for further study would be to apply statistical clustering techniques to the vulnerability data to identify groups of communities that are similar.

In sum, the illustration suggests that HVSI can be most effective as a tool for communities if it is implemented in an online platform that allows the user to: access both summary assessments and detailed data; customize queries; and access appropriate analytical summaries (e.g., tables and figures) as well as interpretation guidelines to support 
identifying similar and dissimilar places in an efficient manner. Importantly, once the user has identified other communities of interest (e.g., those that are similar in profile and face similar vulnerability issues), the platform should provide information on these communities and some means for investigating them further, such as links to key planning documents or contact persons in those other communities.

\section{Discussion}

This paper has proposed a Hazard Vulnerability Similarity Index (HVSI) and provided a pilot demonstration to illustrate its practical use. Building on research that has developed quantitative indicators of community vulnerability to hazards, particularly for coastal areas, the HVSI approach involves characterizing communities according to a standardized multidimensional profile of vulnerability, then assessing the similarity of different communities in order to identify places that share similar overall profiles and specific attributes. Rather than ranking places by degree of vulnerability, the objective is to find commonalities (or differences) amongst places. The premise is that identifying similar places is useful for purposes of developing networks, sharing resources, and learning relevant lessons. Full specification of the HVSI framework in terms of specific indicators and variables remains a priority for further research, along with other research areas discussed in Sect. 4 above. The demonstration provided here, however, clearly illustrates the value of the approach.

We suggest that a similarity-based approach does not obviate the need for ranking or identifying places with high vulnerability, but complements such studies by helping communities to gain connections that may help in reducing their vulnerability. Further research might revisit the results of prior hazard vulnerability studies (e.g., those that quantified SoVI or other vulnerability indices) using the lens of similarity-for example, identifying places within a country that have high infrastructure vulnerability but low social vulnerability.

Several networks for promoting disaster resilience have been developed in recent years. The Community \& Regional Resilience Institute (CARRI) has developed a Community Resilience System (CRS) that provides tools, guidance, and information-including documentation of pilot examples-to help communities to assess and enhance their disaster resilience (www.resilientus.org, accessed 8/29/14). The 100 Resilient Cities initiative of the Rockefeller Foundation aims to help cities globally to become more resilient to a range of challenges by providing selected cities with seed funding, guidance, access to resources, and notably, participation in "a global network of member cities who can learn from and help each other" (www.100resilientcities.org, accessed 8/29/14). These networks provide valuable resources and inspiration for communities that are interested in investing in disaster resilience.

We suggest that the effectiveness of such networks could be enhanced if a filter such as the HVSI were applied to help communities that are similar to connect with one another. For instance, while all coastal communities will face sea-level rise, global cities such as New York will have different infrastructural challenges and financial resources than a small fishing town. For the latter, information on how other fishing towns are addressing sea-level rise would be arguably more relevant and useful than reports on New York City's initiatives. Such connections may reveal knowledge gaps that are common to many communities of a particular type, where research could be effectively prioritized. 
We believe that an important use of the HVSI will be for learning, in particular, for transferring lessons from prior disasters to communities that have not experienced such events. The literature on disaster impacts is rich in case studies, but it is difficult to discern which case studies are most relevant to which communities. Clearly, the experiences of New York City during Hurricane Sandy and its efforts to build resilience to future storms are unique in many ways and not directly transferrable to tourist towns, fishing villages, or even many coastal cities. Yet New York's experiences and efforts are by now very wellknown, well documented, and accessible.

In contrast, many other disasters that are less well-known may be more relevant in terms of learning about the potential impacts of hazards. For example, many small coastal communities in British Columbia face potential risks from tsunamis and undersea landslides (Clague and Bobrowsky 2010). It may be useful for them to learn about the relatively obscure yet highly relevant case of Valdez, Alaska, a remote coastal community that was severely affected by the 1964 Great Alaska earthquake. Shaking in that event caused an undersea landslide that generated a massive local tsunami that destroyed the town's port facilities. The main tsunami from the subduction earthquake followed, inundating the downtown and causing massive urban fires; in the recovery, the town was relocated to higher ground (http://www.usc.edu/dept/tsunamis/alaska/1964/webpages/ 1964valdez.html, accessed 9/1/14). One potentially fruitful application of the HVSI would be to link communities with relevant disaster cases based on key vulnerability indicators or profiles, so that their lessons can be made more accessible. Facilitating such learning would be an important step toward building the disaster resilience of coastal communities.

Acknowledgments This research was supported by the Marine Environmental Observation Prediction and Response (MEOPAR) Network of Centres of Excellence. We thank two anonymous reviewers for their suggestions and acknowledge the contributions of research assistants Christopher Carter, Tugce Conger, and Michelle Marteleira and postdoc Greg Oulahen in implementing the case study.

Open Access This article is distributed under the terms of the Creative Commons Attribution 4.0 International License (http://creativecommons.org/licenses/by/4.0/), which permits unrestricted use, distribution, and reproduction in any medium, provided you give appropriate credit to the original author(s) and the source, provide a link to the Creative Commons license, and indicate if changes were made.

\section{References}

Adger WN, Brooks N, Bentham G, Agnew M, Eriksen S (2004) New indicators of vulnerability and adaptive capacity. Tyndall Centre Technical Report 7. Tyndall Centre for Climate Change Research, Norwich

Balica SF, Wright NG, van der Meulen F (2012) A flood vulnerability index for coastal cities and its use in assessing climate change impacts. Nat Hazards 64(1):73-105

Birkmann J, Cardona OD, Carreno ML, Barbat AH, Pelling M, Schneiderbauer S et al (2013) Framing vulnerability, risk and societal responses: the MOVE framework. Nat Hazards 67(2):193-211

Bjarnadottir S, Li Y, Stewart MG (2011) Social vulnerability index for coastal communities at risk to hurricane hazard and a changing climate. Nat Hazards 59(2):1055-1075

British Columbia Ministry of Forests, Lands, and Natural Resource Operations (2012) Potential year 2100 coastal floodplain areas in British Columbia. http://www.env.gov.bc.ca/wsd/public_safety/flood/pdf_ drawings/index.html. Accessed 10 Aug 2014

Bruneau M, Chang SE, Eguchi RT, Lee GC, O’Rourke TD, Reinhorn AM, Shinozuka M, Tierney K, Wallace WW, von Winterfeldt D (2003) A framework to quantitatively assess and enhance the seismic resilience of communities. Earthq Spectra 19(4):733-752

Burton CG (2010) Social vulnerability and hurricane impact modeling. Nat Hazards Rev 11(2):58-68 
Chakraborty J, Tobin GA, Montz BE (2005) Population evacuation: assessing spatial vulnerability in geophysical risk and social vulnerability to natural hazards. Nat Hazards Rev 6(1):23-33

Clague J, Bobrowsky P (2010) Natural hazards in Canada. Geosci Can 37(1):17-37

Cutter SL, Finch C (2008) Temporal and spatial changes in social vulnerability to natural hazards. Proc Natl Acad Sci 105(7):2301-2306

Cutter SL, Boruff BJ, Shirley WL (2003) Social vulnerability to environmental hazards. Soc Sci Q 84(2):242-261

Cutter SL, Barnes L, Barry M, Burton C, Evans E, Tate E, Webb J (2008) A place-based model for understanding community resilience to natural disasters. Glob Environ Change 18:598-606

Deshpande R, VanderSluis B, Myers CL (2013) Comparison of profile similarity measures for genetic interaction networks. PloS One 8(7):e68664. doi:10.1371/journal.pone.0068664

Fekete A (2012) Spatial disaster vulnerability and risk assessments: challenges in their quality and acceptance. Nat Hazards 61:1161-1178

Felsenstein D, Lichter M (2014) Social and economic vulnerability of coastal communities to sea-level rise and extreme flooding. Nat Hazards 71(1):463-491

Furr RM, Wood D (2013) On the similarity between exchangeable profiles: a psychometric model, analytic strategy, and empirical illustration. J Res Personal 47(3):233-247

Gan G, Ma C, Wu J (2007) Similarity and dissimilarity measures. In: Gan G, Ma C, Wu J (eds) Data clustering: theory, algorithms, and applications. Society for Industrial and Applied Mathematics, Philadelphia, pp 67-106

Gower JC (1971) A general coefficient of similarity and some of its properties. Biometrics 27(4):857-871

Hallegatte S, Green C, Nicholls RJ, Corfee-Morlot J (2013) Future flood losses in major coastal cities. Nat Clim Change 3:802-806

Hastings A, Gross LJ, Ebooks C (2012) Encyclopedia of theoretical ecology. University of California Press, Berkeley

Holand IS, Lujala P (2013) Replicating and adapting an index of social vulnerability to a new context: a comparison study for Norway. Prof Geogr 65(2):312-328

Huang Y, Li F, Bai X, Cui S (2012) Comparing vulnerability of coastal communities to land use change: analytical framework and a case study in China. Environ Sci Policy 23:133-143

Jones B, Andrey J (2007) Vulnerability index construction: methodological choices and their influence on identifying vulnerable neighborhoods. Int J Emerg Manag 4(2):269-295

Kienberger S (2012) Spatial modelling of social and economic vulnerability to floods at the district level in BA(0)zi, Mozambique. Nat Hazards 64(3):2001-2019

McLaughlin S, Cooper JA (2010) A multi-scale coastal vulnerability index: a tool for coastal managers? Environ Hazards 9(3):233-248

Mustafa D, Ahmed S, Saroch E, Bell H (2011) Pinning down vulnerability: from narratives to numbers. Disasters 35(1):62-86

National Research Council (2006) Facing Hazards and Disasters: Understanding Human Dimensions. The National Academies Press, Washington, DC

National Research Council (2012) Disaster resilience: a national imperative. The National Academies Press, Washington, DC

Orencio PM, Fujii M (2012) An index to determine vulnerability of communities in a coastal zone: a case study of Baler, Aurora, Philippines. Ambio 42:61-71. doi:10.1007/s13280-012-0331-0

Oulahen G, Mortsch L, Tang K, Harford D (2015) Unequal vulnerability to flood hazards: "ground truthing" a social vulnerability index of five municipalities in Metro Vancouver, Canada. Ann Assoc Am Geogr 105(3):473-495

Peacock WG (2010). Advancing the resilience of coastal localities: developing, implementing and sustaining the use of coastal resilience indicators: a final report. Hazard Reduction and Recovery Center, College Station. http://hrrc.arch.tamu.edu/publications/reports/. Accessed 13 April 2014

Rygel L, O'Sullivan D, Yarnal B (2006) A method for constructing a social vulnerability index: an application to hurricane storm surges in a developed country. Mitig Adapt Strateg Glob Change 11:741-764

Santos C et al (2013) Quantitative assessment of the differential coastal vulnerability associated to oil spills. J Coast Conserv 17:25-36

Tate E (2012) Social vulnerability indices: a comparative assessment using uncertainty and sensitivity analysis. Nat Hazards 63:325-347

Torresan S, Critto A, Rizzi J, Marcomini A (2012) Assessment of coastal vulnerability to climate change hazards at the regional scale: the case study of the North Adriatic Sea. Nat Hazards Earth Syst Sci 12(7):2347-2368 
Wood NJ, Burton CG, Cutter SL (2010) Community variations in social vulnerability to Cascadia-related tsunamis in the US Pacific Northwest. Nat Hazards 52(2):369-389

Wu S-Y, Yarnal B, Fisher A (2002) Vulnerability of coastal communities to sea level rise: a case study of Cape May County, New Jersey, USA. Clim Res 22:250-270 